ORIGINAL RESEARCH

\title{
Physical and Medical Characteristics of Successful and Unsuccessful Summiteers of Mount Everest in 2003
}

\author{
Colette Wiseman, BS; Luanne Freer, MD, FACEP; Erick Hung, MD \\ From the University of Chicago Pritzker School of Medicine, Chicago, IL (Wiseman); the Himalayan Rescue Association, Everest Base \\ Camp Medical Clinic, Nepal, Bozeman, MT (Dr Freer); and the University of California, San Francisco, CA (Dr Hung).
}

\begin{abstract}
Objectives.-To describe physiological attributes (height, weight, sex, resting heart rate, etc) of climbers attempting to summit Mt Everest and to investigate differences between successful and unsuccessful summiteers.

Methods.- One-hundred thirteen Everest climbers were surveyed by questionnaire before and after the spring 2003 climbing season. Climbers' previous high-altitude climbing experience and physical characteristics were recorded, as well as health before and during expedition, medication used, body weight before expedition and after summit attempt, and ultimate summit success or failure.

Results.-The most common afflictions among climbers were cough, diarrhea, nausea, and vomiting, and the most common medications used were acetazolamide, aspirin, and antibiotics. Average postacclimatization, presummit "rest" altitude was $4571 \mathrm{~m}$, and average weight carried $10.7 \mathrm{~kg}$. Average body mass loss during expedition, regardless of success, was $7 \%$.

Conclusions. - Oxygen use and existence of gastrointestinal disorders are strongly correlated with success in summiting Mt Everest. On the other hand, a history of acute mountain sickness before the attempt is correlated with failure in summiting Mt Everest. Several other factors were found to be marginally correlated with chance of success, but the power of the study was limited by a low postsummit attempt questionnaire return rate $(34 \%)$.
\end{abstract}

Key words: altitude, altitude sickness, mountaineering, physical fitness, snow sports, sports medicine, oxygen

\section{Introduction}

Many factors affect performance of mountaineers at altitude, including underlying medical conditions, genetics, diet, acclimatization schedule, psychological factors, weather, training, oxygen use, mountaineering experience, and expedition support. In 2003, 264 climbers summited Mt Everest ( $8848 \mathrm{~m}$ ), setting a new record for most summits from all routes combined in 1 year, a record that was broken yet again in 2004 with 330 successful summits. Multiple factors doubtlessly interact to influence success, and these may include (but are not necessarily limited to) factors such as weight (muscle mass) lost, medication used, previous high-altitude climbing experience, or weight carried on the summit attempt. This study queried 113 climbers attempting to

Corresponding authors: Colette Wiseman, BS, 5050 South Lake Shore Drive \#2417, Chicago, IL 60615 (e-mail: col@uchicago.edu); and Luanne Freer, MD, 220 Deer Path, Bozeman, MT 59718 (e-mail: LuanneFreer@gmail.com). summit Mt Everest to identify variables predicting likelihood of success vs failure. The study also documents and quantifies health problems encountered by climbers, data that are likely to prove useful to future expedition planning.

\section{Methods}

The study was conducted at Everest Base Camp, Nepal (5350 m). All English speaking climbers present at Everest Base Camp during the spring 2003 season were asked to participate in a 2-step questionnaire comprised of 1 pre-summit-attempt survey conducted by staff and 1 post-summit-attempt questionnaire completed by the climber and returned by email. The presummit survey contained background information such as past climbing experience and past medical history. The postsummit survey contained questions about expedition and medical history (including postexpedition weight) during summit attempts. 
Table 1. Summary statistics comparing subjects who returned follow-up questionnaires and those who did not*

\begin{tabular}{|c|c|c|c|c|}
\hline & \multicolumn{2}{|c|}{ Mean } & \multicolumn{2}{|c|}{$S D$} \\
\hline & Non-follow-ups & Follow-ups & All subjects & Follow-ups \\
\hline Number of subjects & 75 & 38 & & \\
\hline Original weight (kg) & 74 & 76 & 10.84 & 12.36 \\
\hline Height $(\mathrm{cm})$ & 176 & 179 & 8.80 & 8.81 \\
\hline Original $\mathrm{BMI} \dagger$ & 23.8 & 23.7 & 2.42 & 2.48 \\
\hline Oxygen saturation $(\%)$ & $83 \%$ & $82 \%$ & 3.95 & 4.18 \\
\hline Heart rate & 85 & 83 & 15.19 & 16.02 \\
\hline Male ( $\%$ of total) & 93 & 87 & & \\
\hline Age (years) & 41.0 & 38.2 & 9.04 & 7.51 \\
\hline \multicolumn{5}{|l|}{ Continent of residence ( $\%$ of total) } \\
\hline North America & 28 & 55 & & \\
\hline South America & 0 & 5 & & \\
\hline Europe & 60 & 24 & & \\
\hline Asia & 7 & 3 & & \\
\hline Africa & 5 & 11 & & \\
\hline Australia & 0 & 3 & & \\
\hline No. of previous Everest attempts & 0.83 & 0.58 & 1.31 & 1.15 \\
\hline No. of previous Everest summits & 0.21 & 0.13 & 0.56 & 0.48 \\
\hline No. of previous $8000-\mathrm{m}$ mountain attempts & 1.57 & 1.26 & 2.03 & 1.83 \\
\hline No. of previous $8000-\mathrm{m}$ mountain summits & 0.65 & 0.40 & 1.04 & 1.00 \\
\hline
\end{tabular}

*The mean values in the overall populations as well as the mean values among the follow-ups are known; from this, the mean values among non-follow-ups were deduced.

$\dagger$ BMI indicates body mass index, (weight $[\mathrm{kg}] /[\text { height }(\mathrm{m})]^{2}$ ).

Climbers who did not speak English were excluded from the study, as were climbers who were attempting anything other than Mt Everest's South Col route.

Each climber completed a presummit questionnaire as well as measurement of weight on a portable scale, heart rate via pulse measurement, and pulse oximetry via a portable pulse oximeter. In June 2003, all 113 climbers received the secondary questionnaire via e-mail. If there was no response, the secondary questionnaire was sent twice more in a 3-month period. A total of 38 climbers returned the secondary questionnaire.

Although the total number of climbers attempting Mt Everest via the South Col in 2003 was not available, in past years approximately $34 \%$ of climbers attempting this route successfully summited. If 264 climbers successfully summited Everest in 2003, and they represented $34 \%$ of all climbers attempting to summit, we assume that approximately 776 climbers made attempts. Therefore, the 113 climbers replying to the initial survey probably represent approximately $15 \%$ of total climbers, and the 38 climbers replying to the postexpedition survey represented approximately 5\% of all South Col Everest climbers in 2003.

In evaluating the collected data, statistical significance was established at $p<0.05$.

\section{Results}

One-hundred thirteen climbers completed the initial interview, and 38 returned the secondary survey.

\section{CHARACTERISTICS OF CLIMBERS BEFORE SUMMIT ATTEMPT}

Ninety-three percent of the climbers surveyed were male. The average height, weight, and age of Englishspeaking Everest climbers were $164 \mathrm{~cm}, 57 \mathrm{~kg}$, and 36 years (female) and $178 \mathrm{~cm}, 76 \mathrm{~kg}$, and 40 years (male). At Everest Base Camp $(5350 \mathrm{~m})$ before the summit attempt, the average heart rate among climbers was 82 and the average oxygen saturation was $84 \%$ (see Table 1).

Eighty-seven percent of climbers took prescription or over-the-counter medications at some time before the summit attempt. The most common medications used were aspirin (25\%), acetazolamide (24\%), ciprofloxacin (13\%), and azithromycin (5\%). The most common medical conditions reported during the trek to Everest Base Camp were diarrhea (30\%), chronic cough (24\%), upper respiratory infection/common cold (20\%), and fever (18\%) (see Table 2). 
Table 2. Medical conditions and medications reported during trek to Everest Base Camp (Total subjects $=113$ )

\begin{tabular}{lcc}
\hline & \% of climbers & No. of climbers \\
\hline Medical condition & & \\
Diarrhea & 30 & 34 \\
Vomiting & 10 & 11 \\
Chronic cough & 24 & 27 \\
Upper respiratory infection (cold) & 20 & 22 \\
Fever & 18 & 20 \\
Medication & & 29 \\
Antibiotics & 26 & 27 \\
Acetazolamide & 24 & 8 \\
Pulmonary drugs (albuterol, solumedrol/dexamethasone/fluticasone) & 7 & 4 \\
Acid reducers & 3.5 & \\
\hline
\end{tabular}

\section{FOLLOW-UP OF CLIMBERS AFTER SUMMIT ATTEMPT: SUCCESS VS FAILURE}

Because only one third of the original participants returned the follow-up questionnaire, a comparison of the 2 groups (follow-ups vs non-follow-ups) was performed, with the results shown in Table 1. The conclusion of this analysis was that the 2 groups are comparable in both physical and experience-related statistics; however, they differ in geographical location, with more North Americans and fewer Europeans following up. This conclusion was based on the observation that the average values of variables in each group (age, height, previous 8000-m mountains attempted) fell within the standard deviation of the original sample, and therefore was not significantly different.

Most climbers reported some illness during their summit bid. The most common afflictions were cough (19/ 38 ), diarrhea (14/38), and nausea/vomiting (7/38). Seventy-five percent of the climbers who attempted to summit Mt Everest took prescription or over-the-counter medications at some point during their summit attempt. Aspirin was the most commonly used drug during the summit attempt (25\%).

Seventeen of the 38 climbers who returned the postattempt survey were successful summiteers. Physical, geographic, and experience-related statistics of both successful and unsuccessful summiteers are shown in Table 3. Many of the demographic and medical variables measured showed no correlation with success or failure. Table 3 shows some correlations of interest between many of the measured variables, and the success vs failure of the subjects. It is immediately obvious that successful summiteers are more likely to use oxygen ( $94 \%$ vs $58 \%$, $t=3.68)$. On the other hand, unsuccessful summiteers are more likely to have a previous history of acute mountain sickness (AMS) $(67 \%$ vs $35 \%, t=1.97)$. Several other variables also appear strongly correlated, although the small sample size prevents significant inference. These variables include height; current pulmonary, gastrointestinal, orthopedic, or altitude illness; taking over-the-counter or alternative medicines; gender; being from North America or South America; a previous 8000m summit attempt; a previous 8000 -m summit success; a history of high-altitude pulmonary edema; and a history of frostbite.

All of the above "promising" variables were regressed in a multivariate logistic regression to measure their joint correlation with success (See Table 4). The results mirror the findings described above. Therefore, each of the significant differences we observed appears to operate even when the other "effects" are statistically controlled for.

\section{Discussion}

These data provide an interesting summary of characteristics of climbers attempting the summit of Mt Everest in 2003. In addition, we found several significant and strong correlates of success.

The use of supplemental oxygen was found to be strongly correlated with success in summiting Mt Everest. It has been common practice since the first ascent of Mt Everest to use supplemental oxygen because of the extreme altitude of the mountain. Although using supplemental oxygen involves carrying a heavier weight, its benefits include an increase in physical strength and stamina, as well as mental clarity, better decision-making, and a more positive attitude. Although climbers are well aware of all of these factors, some may choose to climb without oxygen to test their physical 
Table 3. Correlates of success

\begin{tabular}{|c|c|c|c|c|c|c|c|}
\hline & \multicolumn{2}{|c|}{ Unsuccessful } & \multicolumn{2}{|c|}{ Successful } & \multicolumn{3}{|c|}{$\begin{array}{c}\text { Difference (Successful - } \\
\text { Unsuccessful) }\end{array}$} \\
\hline & Mean & $S D$ & Mean & $S D$ & Mean & $S D$ & $P$ \\
\hline Height (m) & 177.00 & 9.21 & 180.41 & 8.16 & 3.41 & 2.82 & .227 \\
\hline Pulmonary illness $(\%)$ & 43 & 51 & 53 & 51 & 10 & 17 & .549 \\
\hline Gastrointestinal illness (\%) & 38 & 50 & 59 & 51 & 21 & 16 & .207 \\
\hline Bone or muscle injury (\%) & 10 & 30 & 0 & 0 & -10 & 7 & .148 \\
\hline Altitude illness (\%) & 24 & 44 & 12 & 33 & -12 & 12 & .336 \\
\hline Oxygen used on summit attempt (\%) & 48 & 51 & 94 & 24 & 47 & 13 & .0001 \\
\hline Over-the-counter medicine used (\%) & 38 & 50 & 53 & 51 & 15 & 17 & .371 \\
\hline Alternative medicine used (\%) & 48 & 51 & 35 & 49 & -12 & 16 & .452 \\
\hline Male $(\%)$ & 81 & 40 & 94 & 24 & 13 & 11 & .215 \\
\hline From North America (\%) & 48 & 51 & 65 & 49 & 17 & 16 & .296 \\
\hline From South America (\%) & 10 & 30 & 0 & 0 & -10 & 7 & .148 \\
\hline No. of previous $8000-\mathrm{m}$ mountain attempts & 0.95 & 1.36 & 1.65 & 2.26 & 0.70 & 0.62 & .265 \\
\hline No. of previous $8000-\mathrm{m}$ mountain summits & 0.14 & 0.48 & 0.71 & 1.36 & 0.56 & 0.35 & .103 \\
\hline History of $\mathrm{AMS}^{* \dagger}$ & 67 & 48 & 35 & 49 & -31 & 16 & .049 \\
\hline History of HAPE $\dagger$ & 0 & 0 & 24 & 66 & 24 & 16 & .145 \\
\hline History of frostbite & 14 & 36 & 35 & 49 & 21 & 14 & .142 \\
\hline Total number of subjects & \multicolumn{2}{|c|}{21} & \multicolumn{2}{|c|}{17} & & & \\
\hline
\end{tabular}

*Large, significant difference between the two groups (unsuccessful vs successful).

$\dagger$ AMS indicates acute mountain sickness. HAPE indicates high attitude pulmonary edema.

and mental endurance. Among our subjects, 94\% who summited used oxygen, whereas only $48 \%$ of those who failed to summit used oxygen.

A history of AMS is strongly correlated with failure in summiting Mt Everest. This suggests that some individuals may be more susceptible to developing AMS. This addresses a controversial issue in the world of highaltitude medicine: whether some people are more susceptible to high-altitude illnesses. It is interesting to note that there was no significant difference in the complaints of current (ie, on this particular expedition) AMS among summiteers and nonsummiteers. Whether our correlation is because of an actual physiologic tendency toward AMS that causes decreased physical conditioning, or whether the fear of redeveloping AMS in a person causes the person to perform at a lower level, remains to be seen.

Perhaps our most interesting finding is the strong correlation of the existence of gastrointestinal illness such as vomiting and diarrhea with a successful summit of Mt Everest. However, this correlation was not quite strong enough to be significant $(t=1.91$; statistical significance requires $t=1.96$ ) and therefore could be because of the small sample size of the study. Further study looking at this particular variable should illuminate whether a correlation exists.

\section{OTHER FINDINGS OF NOTE}

Several interesting findings in the data, although not predictive of success or failure, are worth mentioning.

A histogram of previous altitude ever attained (Figure 1) shows a distinct peak at about $7000 \mathrm{~m}$. This is likely because of the influence of Mt Aconcagua in South America, a popular training ground for would-be Mt Everest summiteers. Although highest previous altitude ever attained initially appears to be a good measure of a climber's experience, the natural paucity of high-altitude peaks and the strong bias of climbers summiting Mt Aconcagua means that it is not possible, with our data, to determine depth of experience. Many of the climbers in this study may have climbed only once at high altitude, with very little other experience.

A histogram of postacclimatization presummit altitude ("rest" altitude) is shown in Figure 2. This is the lowest altitude that a climber descends to after weeks of acclimatization, just before his or her final summit bid. Much controversy exists about what altitude a climber should descend to just before the summit bid. Although we did not find that descent altitude significantly affected a climber's chance of success, it is interesting to note that the majority of rest altitudes were between 3800 and $5400 \mathrm{~m}$, with the majority of these at $5400 \mathrm{~m}$, which correlates with Everest Base Camp. 
Table 4. Multivariate analysis of the correlates of success*

\begin{tabular}{|c|c|c|c|c|c|c|}
\hline Variable & Parameter & Standard Error & $\mathrm{t}$ & Odds Ratio & \multicolumn{2}{|c|}{$95 \%$ Confidence Interval } \\
\hline Constant & 5.048 & 7.575 & 0.67 & & & \\
\hline Male gender $($ male $=1$, female $=0)$ & 2.145 & 1.944 & 1.10 & 8.44 & 0.19 & 376.43 \\
\hline Original BMI & -0.320 & 0.277 & -1.16 & 0.73 & 0.42 & 1.25 \\
\hline PAPS & -0.001 & 0.001 & -1.29 & 1.00 & 1.00 & 1.00 \\
\hline Oxygen used $\dagger$ & 3.492 & 1.473 & 2.37 & 33.13 & 1.83 & 598.25 \\
\hline Previous $8000-\mathrm{m}$ summit attempt & 1.035 & 0.658 & 1.57 & 2.80 & 0.77 & 10.13 \\
\hline Weight carried (kg) & 0.135 & 0.199 & 0.68 & 1.15 & 0.78 & 1.69 \\
\hline Current AMS & 0.465 & 1.419 & 0.33 & 1.59 & 0.10 & 25.60 \\
\hline History of AMS $\dagger$ & -2.117 & 1.150 & -1.89 & 0.11 & 0.01 & 1.08 \\
\hline Gastrointestinal illness $\dagger$ & 2.493 & 1.309 & 1.91 & 12.06 & 0.93 & 156.30 \\
\hline
\end{tabular}

*Logistic regression was estimated, regressing the variables shown on the probability of success. Large $t$-values (below -1.96 and above +1.96) indicates significance. The magnitude of the parameter estimates is not readily interpretable. BMI indicates body mass index; PAPS, postacclimatization presummit altitude; and AMS, acute mountain sickness.

$\dagger$ Significant or nearly-significant estimate.

The main factor making the data difficult to extrapolate to other climbers and even other climbers on Everest is the small number of subjects, which renders most of the trends statistically insignificant.

One caveat to interpreting these data is the "third factor" effect. Because this was a case series study and not a double-blind controlled study, it is easy to demonstrate a correlation, but difficult to demonstrate a cause-andeffect relationship between 2 variables such as use of a particular medication and successful summit. For example, climbers on more affluent sponsored expeditions may have better access to varied nutrition, nutritional supplements, more experienced or multiple guides, or better equipment and training, resulting in their successful ascent; this does not suggest a cause-and-effect re-

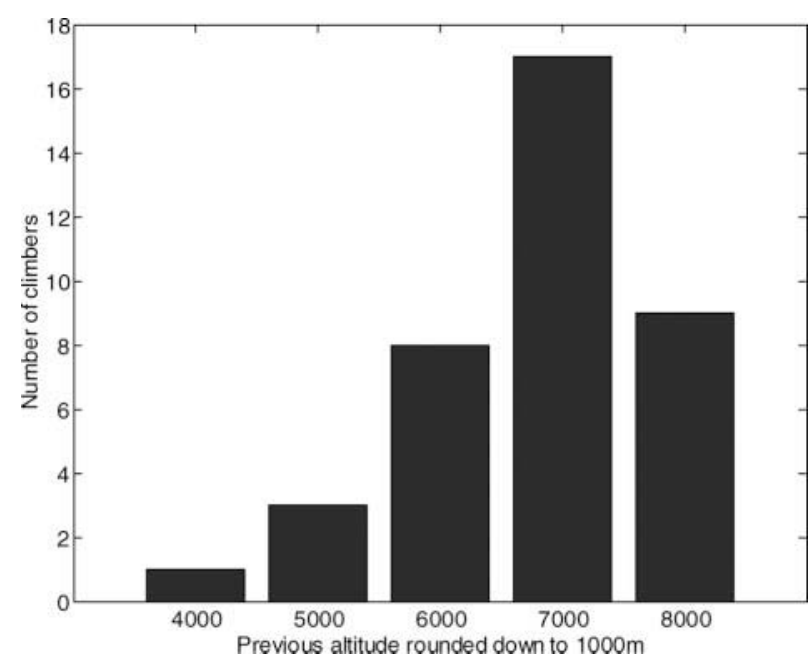

Figure 1. Previous maximum altitude attained by climbers before this study. lationship between use of a particular medication and summit success.

\section{Conclusions}

This study provides a description of interesting characteristics of English-speaking Everest climbers. The analysis of common medications, illnesses, and physical characteristics of Everest climbers will hopefully help future climbers and expeditions with their planning to improve success and decrease morbidity and mortality.

Supplemental oxygen use and no personal history of AMS are clearly correlated with successful summiting. In addition, we have found suggestions that variables such as reports of gastrointestinal illness, other illness, medication use, and previous experience may be corre-

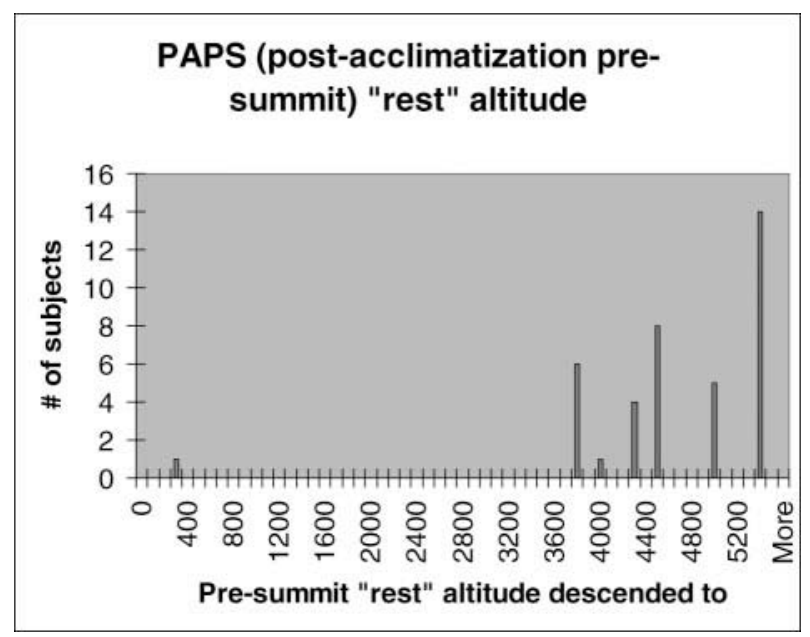

Figure 2. Presummit "rest" altitude. 
lated with success, but a larger sample size is needed to yield meaningful results. Future research focusing on such issues will, we hope, elicit answers to these interesting questions.

\section{Acknowledgment}

We would like to thank Professor Robert Zeithammer for assistance with statistical analysis of study data.

\section{References}

1. Huey RB, Salisbury R. Success and death on Mt Everest. Am Alpine J. 2003:1-10.
2. Rodway GW, Hoffman LA, Sanders MH. High-altituderelated disorders - part I: pathophysiology, differential diagnosis, and treatment. Heart Lung. 2003;32:353359.

3. Gertsch JH, Basnyat B, Johnson EW, Onopa J, Holck PS. Randomised, double blind, placebo controlled comparison of ginkgo biloba and acetazolamide for prevention of acute mountain sickness among Himalayan trekkers: the prevention of high altitude illness trial (PHAIT). BMJ. 2004;328: 797.

4. Bartsch P, Bailey D, Berger M, Knauth M, Baumgartner R. Acute mountain sickness: controversies and advances. High Alt Med Biol. 2004;5:110-124.

5. Bradwell AR, Dykes PW, Coote JH, et al. Effect of acetazolamide on exercise performance and muscle mass at high altitude. Lancet. 1986;1:1001-1005. 